Counting Differently: Assessing Mathematics Achievement in Signing Deaf and Hard of Hearing Children Through a Unique Lens

Jon Henner

Claudia Pagliaro

SaraBeth Sullivan

Robert Hoffmeister

Henner, J., Pagliaro, C.,. Sullivan, S., \& Hoffmeister, R. (in press). Counting differently: Assessing mathematics achievement in signing deaf and hard of hearing children through a unique lens. American Annals of the Deaf 


\begin{abstract}
Limited studies exist that connect using signed language with mathematics performance in deaf and hard of hearing children. Here we examine 257 participants and compare their results on the NWEA MAP to their results on an assessment of ASL skills. We found that better ASL skills tended to result in better MAP performance. These results are moderated by factors such as age, gender, parental hearing status, and learning disability identification.
\end{abstract}

Keywords: deaf; language; ASL; mathematics 


\section{Counting Differently: Assessing Mathematics Achievement in Signing Deaf and Hard of Hearing Children Through a Unique Lens}

For decades, studies have presented the mathematics achievement of deaf and hard of hearing (DHH) students as trailing behind their hearing peers (Mitchell, 2008; Traxler, 2000). Many of these academic analyses tend to focus on averages (notably medians), which can mask the true variability within the dataset and create a focus on delays and deficiencies. Hidden from view is a more complex picture of the mathematics abilities of DHH children, including in particular those who perform above the so-called average and those on grade level or above.

Although there are relatively few studies that focus specifically within these broad contexts, those that do find that $\mathrm{DHH}$ learners demonstrate equal or superior abilities in numeracy when compared to their age equivalent hearing counterparts (Arfè, et al., 2011; Barbosa, 2013; Zarfaty, Nunes, \& Bryant, 2004). DHH learners, preschool through post high school (including college-level DHH adults) have demonstrated age-appropriate mathematics skills (Kritzer, 2009; Lange, Lane-Outlaw, Lange, \& Sherwood, 2013; Qi \& Mitchell, 2001; Pagliaro \& Ansell, 2012; Traxler, 2000). Little is known, however, as to why these DHH children succeed in mathematics while others struggle. In the current investigation, a more comprehensive view of student achievement and exploration of multiple factors that may contribute to the mathematics performance provide insight and constructive direction to those working with DHH children and youth.

\section{Language and Mathematics}

Research has long recognized the relationship between language and academic success (Cummins, 1982; Chen \& Li, 2008) including mathematics (Secada, 1992). To truly learn mathematics, one must engage with it and communicate about it through language. While 
philosophers argue about whether mathematics itself is a language (e.g. Krussel, 1998), we make no such distinction here; mathematics is both a language and a system of operations performed on numbers. Similarly, as with language, one must be involved with mathematics in contexts that have meaning and purpose, at increasingly higher and broader cognitive levels to succeed in education (Wang, Jiang, \& Fan, 2017). Skills learned in mathematics and language scaffold one another to create an interdependent relationship, allowing the learner to simultaneously build both capacities. These skills develop with age and experience through infancy (Baldo \& Dronkers, 2007; Halvorsen \& Molfese, 2016), preschool (Le Fevre et al., 2010; Mix, 2009; Purpura, et al., 2011) and elementary (Toll \& VanLuit, 2014) years. Further in academics, mathematical thinking supports and encourages higher-order thinking and executive function (e.g., organization, problem solving, inference, and supporting arguments) that must be expressed in equally higher-order language. Research shows that children and adults who have language and literacy difficulties often experience numeracy challenges as well (Mann Koepke, \& Miller, 2013; De Smedt et al., 2010; Simmons et al., 2008).

More recent work in this area has focused on students whose native language is not the language of instruction (e.g., English language learners in the U.S.). In general, learners with a strong first language (L1) and second language (L2) perform best in mathematics, even better than monolinguals (Chen \& Li, 2008; Hartanto, Yang, \& Yang, 2018). Among bilinguals, studies show that mathematics presented in students' L1 is positively correlated with achievement (Bernarndo \& Calleja, 2005; Perez \& Alieto, 2018). But what of those with language deprivation who struggle to achieve across all academic subjects, including mathematics? Many of these studies include investigations involving DHH students and illustrate the correlation between English proficiency and mathematics performance. Poor English language skills are associated 
with lower performance in mathematics, particularly as complexity in mathematics concepts progresses and the English within becomes more complicated (e.g., Davis \& Kelly, 2003; Edwards, Edwards, \& Langdon, 2013; Hyde et al., 2003; Kelly \& Gaustad, 2006; Kelly, Lang, \& Pagliaro, 2003; Kelly \& Mousley, 2001). For example, in a study of DHH adults attending postsecondary institutions (age 19-34), results showed that those who demonstrated higher levels of written English vocabulary also demonstrated higher levels in mathematics (Kelly \& Gaustad, 2006). Most importantly, their scores on the ACT mathematics assessments and the English language and morphological assessments were correlated not only with each other but also with actual grades from the college-level mathematics classes they took. We recognize that the focus on English and ASL limits the generalization of the studies to populations from the States, yet these studies can likely be generalized to populations of DHH people in other countries since the conflict between signed and spoken languages are relatively similar in other countries.

\section{Other Factors Affecting Mathematics Achievement}

Although the link between language proficiency and mathematics skills is established, language abilities are not the sole predictors of mathematics proficiency. How well students respond to teaching strategies and assessment is contingent on a variety of different factors. The basis for this perspective is the Dynamic Systems Theory (DST; de Bot, Lowie, \& Verspoor, 2007). As de Bot et al. (2007) explains, DST began as a mathematics theory to explain how variables interact in complex systems (p. 8). When considering extraordinarily complex systems, such as human beings, the examined variables are influenced by a plurality of other variables, considered and unconsidered. With regard to DHH students, we consider the following variables to be highly influential in learning mathematics: access to language at home (parental hearing status), age, gender, and learning disability 


\section{Access to Language at Home}

In typical language acquisition, children acquire the language of their parents as their first language (L1). The timing and quality of language exposure (regardless of modality) is paramount to establishing critical language pathways in a child (Kuhl, 2004; Newport et al., 2001). Delays in this exposure to language (be it spoken or signed), as often happens with DHH children of hearing parents, can result in varying degrees of language deprivation (Hall, 2017; Humphries et al., 2016; Novogrodsky, Henner, Caldwell-Harris, \& Hoffmeister, 2017). More than $90 \%$ of DHH children are born to hearing parents. Many of these parents choose to present language to their child via spoken English, most likely unaware of the challenges their child faces in accessing oral language and foregoing any signed language learning. As a result many of these DHH children experience great difficulty acquiring their parents' spoken (home) language as an L1 (Lederberg et al., 2013). While some people may question if studies focusing on language deprivation in deaf children can be generalized to children with only mild to moderate hearing loss, research shows that even those children have higher incidences of language disorders than children who do not present with hearing loss (Tuller \& Delage, 2014).

Barriers to first language acquisition (L1) are less evident in Deaf families where the parents are signing Deaf adults. Many DHH children of DHH parents show native proficiency in their L1 similar to what would be expected in a natural oral language acquisition environment. Having naturally signing DHH parents appears to significantly contribute to the language and mathematics performance of DHH children. Native signing DHH children perform exceptionally well on the U.K. General Certificate of Secondary Education exams (GCSEs) ${ }^{1}$ (Powers, 2003). Kritzer (2009), when examining the scores of young DHH children's (ages 4-6) mathematics on

\footnotetext{
${ }^{1}$ U.K. General Certificate of Secondary Education exams (GCSEs)
} 
the Test of Early Mathematics Achievement-3 (TEMA-3; Ginsburg \& Baroody, 2003), found that children with the highest scores tended to have signing DHH parents. Hrastinski and Wilbur (2008) for example, examined the interplay of mathematics skills (drawn from Northwest Evaluation Association: Measures of Academic Progress (NWEA MAP) scores) and ASL language levels (drawn from teacher judgement/school records). Their interpretation of the data showed that ASL proficiency was more important for performance on the NWEA MAP than home language or age of school admission.

Native language proficiency that includes mathematics vocabulary and concept-related language significantly predicts numerical skills (Purpura \& Reid, 2016). Ginsburg \& Baroody (2003), for example, found that children who had more frequent access to mathematics-specific language demonstrated higher skill level in mathematics. Use of "math talk" in the home and classroom has positive correlations with number knowledge and numeracy performance (Susperreguy \& Davis-Kean, 2016; Levine, Suriyakham, Rowe, Huttenlocher, \& Gunderson, 2010). There exists evidence of a correlation between SES and the preponderance of "math talk" (see Suskind et al., 2016), but many of these studies depend on the word gap framework of Hart and Risley (1995) which was unable to be replicated by Sperry, Sperry, and Miller (2019). While Golinkoff et al. (2019) argue that we need to look past the failed replication and focus on the core issue, which is that early vocabulary scaffolds later education; methods do matter too (2019). However, we caution that too much emphasis on only vocabulary development and reading skills for mathematics achievement, as opposed to grammar and other thinking skills may not be productive. Much of this discussion can be summed up by Fuchs et al. (2016). “...we conclude that pathways to calculation and word-reading outcomes are more different than alike" 
(p. 8). Fuchs et al. did not mean that reading and mathematics are disjunct, but that we should not mistake them for identical skillsets.

Many DHH children do not have full access to language environments that saturate them in language. For them, more language input will be beneficial. The relationship between mathematics and language extends to natural signed languages ${ }^{2}$ (Barbosa, 2013; Hrastinski \& Wilbur, 2008; Lange et al., 2013; Madelena, Corria, \& Spinillo, 2020). Use of "math talk" with Deaf preschoolers at home by their parents has also been linked to advancing mathematics performance (Pagliaro \& Kritzer, in prep).

The current study extends Hrastinksi and Wilbur's (2008) exploration of ASL skills and mathematics skills by folding into its conceptual models additional variables that research suggests might influence mathematics achievement such as Age, Gender, and Learning Disability Status.

Age

Age is a typical controlling variable in acquisition studies because as children age, their cognitive capacities improve. Typically, their understanding of numeracy, number cognition, and abilities to handle complex mathematics ideas and operations improves with age (Claudia). We have used Age as a controlling variable in most of our analyses using the ASLAI dataset (see Novogrodsky et al., 2017; and Henner, Caldwell-Harris, Novogrodsky, \& Hoffmeister, 2016 for more discussion about our use of Age as a controlling variable).

Gender

\footnotetext{
${ }^{2}$ We use the phrase "natural signed languages" to distinguish between community emergent signed languages like American Sign Language and British Sign language from constructed and artificial signed systems developed by researchers, laypeople, and educators, such as Signing Exact English which fall under the umbrella term Manually Coded English (MCE).
} 
Gender appears to have a slight effect on mathematics outcomes, favoring boys, particularly with older age groups. While we emphasize that gender should have no effect on mathematics abilities, gender scholars demonstrate that cultures who devalue mathematics abilities in girls and women show depressed mathematics scores in those groups (Seymour, 1995). Meta-analyses on the effects of gender on mathematics achievement for hearing children suggests a small but significant difference between boys and girls in the upper high school grades, where boys demonstrate higher accuracy on more complex mathematics (Lindberg, Hyde, Petersen, \& Linn, 2010; Reilly, Neumann, \& Andrews, 2015).

Gender influence in studies with DHH students differ from those with hearing students. For DHH children educated within an ASL-English bilingual model for at least 4 years in grades 2 through 9, Lange et al. (2013) found gender did not have a significant effect on mathematics achievement. Similar findings came from Kluwin (1994) and Powers (2003) who both determined gender was not significantly related with scores on the mathematics portion of highschool graduation exams in the U.K. (GCSE: Powers, 2003) nor the U.S. (SAT-HI: Kluwin, 1994). It is important to note that, beyond these data from DHH high-school graduates (Kluwin, 1994; Powers, 2003), there is no known further research examining gender and mathematics skills of DHH between grades 9 through 12 in the United States. We do not yet have a rich understanding of how gender might influence mathematics achievement for DHH children. However, we cannot discredit that DHH children may be affected by stereotype threat or embodied beliefs about race, class, gender, and disability, among other identities, that manifest in society and the parents and teachers who create mathematics learning environments (Shapiro \& Williams, 2011). If DHH children have exposure to stereotype threats, then male DHH participants would demonstrate similar better performance on mathematics assessments. 
However, we stress that we believe that language skills (ASL and/or English) are more deterministic for mathematics success in DHH students than gender.

\section{Learning Disability}

Learning disabilities can affect test scores in mathematics and reading. For example, in a study on learning disabilities in young hearing children (kindergarten and grade 1), researchers found that they had a significant effect on measured mathematics knowledge, within the skills of number sets and number estimations, but not counting knowledge (Geary, Hoard, Byrd-Craven, Nugent, \& Numtee, 2007). This suggests that learning disabilities may impact some mathematics skills more than others. Slightly older children (grade 2) who had different types of learning disabilities (mathematics-based, reading-based, or both) all demonstrated below-average mathematics abilities compared to their peers who had no learning disabilities (Cirino, Fuchs, Elias, Powell, \& Schumacher, 2015).

For DHH children, Allen (1986) found that cognitive learning disabilities were a strong predictor of lower outcomes on the mathematics computation portion of the SAT for DHH testtakers in 1974 and $1983(\mathrm{p}<.001)$. In 2003, Powers determined that learning disabilities led to significantly lower results on the GCSEs for high school graduates in the U.K in both 1995 $(\mathrm{p}<.026)$ and $1996(\mathrm{p}<.006)$. These findings indicate learning disabilities influence mathematics performance for high-school graduates. More recently, Lange et al. (2013) found the presence of a 'secondary disability' significantly correlated with the mathematics scores $(p<.05)$ for DHH children (grades 2-9), educated within an ASL/English bilingual approach for at least 4 years. Thus, there is some indication that the presence of a learning disability can significantly affect mathematics outcomes for DHH students from grade 2 through high-school graduation, as seen with hearing students. While there are fairly limited studies on dyscalculia in DHH people, from 
the literature on hearing peers, we expect similar results (Butterworth, 2008; Reigosa-Crespo et al., 2012).

The current study postulates that lack of meaningful access to language may have critical implications for mathematics development. In the context of this data set, we hypothesize that native signing participants who have experienced less language deprivation and more access to mathematics-specific language will perform better on a mathematics achievement assessment than the non-native signing participants. This study extends previous studies, especially the work of Hrastinksi and Wilbur (2008) by exploring the impacts of ASL proficiency, language nativity, age, gender, and learning disability upon the mathematics achievement of DHH children. Specifically, the study seeks to answer the following questions:

(1) How do the MAP Mathematics achievement scores of the DHH participants compare to the appropriate hearing normed mean RTI units for the ages?

(2) What factors (e.g. age, gender, language input (signing status), ASL vocabulary, and learning disability) influence how DHH students perform on the MAP Mathematics subtest? 


\section{Methods}

Participants

Data for this analysis were collected from 257 DHH participants, aged 8-18, who took the American Sign Language Assessment Instrument (ASLAI; Hoffmeister et al., 2013) as part of routine language testing at various schools for the deaf across the United States. Data collection was partially funded with a grant from the U.S. Institute of Education Sciences that lasted from 2010 - 2015. Data collected after the grant ended was facilitated by individual contracts with the schools. Consent prior to 2014 was acquired for participants through parent consent forms. After 2014, consent was given through a "blanket consent" in which parents were required to opt out of testing as testing included all students in each of the schools. Schools that allowed blanket consent were given detailed individual and group results that could be used to craft Individual Education Plan (IEP) goals for ASL language support. The dataset used in this analysis has been used in several other papers published by the Boston University Center for Research and Training, including Henner, Novogrodsky, Caldwell-Harris, \& Hoffmeister, 2018, and Novogrodsky et al., 2017; however, the questions we sought to answer in this specific forum were markedly different.

Thirty-two percent $(\mathrm{N}=82)$ of the participants were considered native signers in that at least one parent was Deaf. Sixty-eight percent $(\mathrm{N}=175)$ were considered to be non-native (i.e., both parents were hearing). We recognize that this Table 1 shows the distribution of participants by age and signing status. 
$<$ INSERT TABLE 1 HERE $>$

Overall, the number of native participants decreased as age increased. The inverse was true for the number of nonnative participants. This seems to align with Henner et al. (2016)'s findings that large numbers of nonnative students tend to transfer to schools for the deaf after the age of 10 . As there is no definitive explanation for why the native student population decreases at schools for the deaf after the age of 12 , additional research is necessary to determine the reasons for this change.

Of the 257 participants, $54 \%(n=140)$ were female and $46 \%(n=117)$ were male. $31 \%(n$ $=79)$ were Asian American or Pacific Islander. 8\% $(n=21)$ were Black. 26\% $(n=68)$ were white, and 35\% (n=89) were Latinx. Participants were also assigned a Student Rating. Student Ratings allowed schools to categorize participants based on the following ratings:

\section{Ratings}

1), whether they had no diagnosed learning disability and none were suspected

2), had no diagnosed learning disability but one was suspected or

3) had a diagnosed learning disability.

Ratings were provided by the participants' schools and were generally made by someone who was familiar with the participant. Forty-two percent $(n=107)$ of the participants were rated as having no disability, and no additional ones were suspected (Rating 1). Forty-five percent ( $\mathrm{n}=$ 116) of the participants were rated as having no disability, and one was suspected but not identified (Rating 2). Thirteen percent of the participants $(n=34)$ had a formal learning disability identified (Rating 3). However, no information about the kind of learning disability the participant has was collected, nor how the learning disability was identified. Table 2 shows the distribution of ratings between native and nonnative participants. 
$<$ INSERT TABLE 2 HERE $>$

The data show that native signers are disproportionately represented in category 1 (no disability), while nonnative signers are disproportionately represented in category 2 (suspected learning disability).

We did not collect information about degree of hearing loss because that information is not applicable to the study without qualitative information about how the individual participants are able to use their hearing loss to access information. That kind of information requires the use of assessments such as the Speech, Spatial, and Qualities of Hearing Scale (Gatehouse \& Noble, 2004). The way we collected data was from the schools, which did not give us access to the ability to use the Scale.

\section{Measures}

ASLAI

The ASLAI is a computerized task assessment of ASL language proficiency. The tasks within the battery measure ASL vocabulary, syntax, reasoning, and literacy proficiency in DHH children aged 3-18. The instrument has been normed on over 2,000 DHH children over the past ten years. The basic structure of the ASLAI is multiple choice, with one stimulus and four possible responses from which participants may select an answer: Figure 1 presents an example from the Antonyms task. The picture on the left shows the stimulus. The four pictures on the right show possible responses from which the test-taker must choose the correct signed response.

Data on participant ASL vocabulary abilities were collected using two of the tasks from the ASLAI battery: Antonyms (Novogrodsky et al. 2014), and Synonyms (Novogrodsky et al. 
2014). These tasks were chosen as they represent in breadth and depth a good measure of ASL overall vocabulary knowledge. Both tasks are described in detail in the articles mentioned above.

\section{$<$ INSERT FIGURE 1 HERE $>$}

Each task is presented in five stages: a) a global instruction phase b) a task instruction phase, where specific directions are given for that particular task (e.g., finding a sign of similar meaning to the prompt for antonyms), c) a practice phase, where the test-taker is shown a model prompt and answer, d) a task phase, where the test-taker proceeds through the questions, and e) a review phase, where participants can go back and change their answers if needed. Responses are scored under an assigned ID number and automatically included in the database in real time.

\section{Measures of Academic Progress: Mathematics Test}

The NWEA MAP is a computer-based English print format, adaptive assessment designed to provide information on student academic growth over time (NWEA, nwea.org). The MAP assessment consists of four major assessment batteries: a) MAP for reading, English language use, and mathematics, b) science, c) primary grades for reading and mathematics, and d) end of course assessments in mathematics (NWEA, nwea.org). All questions are presented in English print requiring the ability to read and knowledge of English. Adaptive tests scale to student abilities. Correct answers track participants to more challenging questions. Missed questions track students to easier questions. Results are presented in RIT values, which represent Rasch Units. The RIT value represents the level of task difficulty at which participants could get the correct answer at least half the time; that is, the level of difficulty at which getting the correct answer is not due to chance. The RIT value is designed so that schools can analyze student growth from year to year. RIT scores range between 100 and 300 and are presented via 
beginning of year norms, middle of year norms, and end of year norms. A student's score (100300) depends on their age and the content area. Content area scores are not considered equivalent: a 180 in Reading and a 180 in Mathematics are not comparable scores.

For this analysis, only data from the Mathematics assessment was used. Additional detail about the use of the MAP with DHH children can be found in Hrastinksi and Wilbur (2016).

\section{Procedures}

Participants completed the ASLAI tasks in groups of 15-20. Testing length for the battery ranged from 3 to 4 hours depending on age of student. Testing at schools typically took up to one week. Smaller schools could be finished in 3 days, while larger schools may have taken up to ten days depending on logistics. Data from the tasks were immediately sent to CRT databases and encrypted to ensure participant confidentiality.

\section{Results}

(1) How do the MAP Mathematics achievement scores of the DHH participants compare to the appropriate hearing normed mean RTI units for the ages?

We first asked how the MAP Mathematics scores of the DHH participants compared to the appropriate normed mean RTI units for their hearing peers. While in general we do not believe that $\mathrm{DHH}$ children should be compared to hearing peers because DHH often have more challenges in acquiring both spoken and written English which can lead to downstream effects, here we do it to demonstrate that different lenses are needed for analyzing data from $\mathrm{DHH}$ children.

The NWEA draws norms from 72,000 to 153,000 student test results from over 1,000 different schools (NWEA, 2015). The sampling is designed to represent the variety of students in 
the United States. MAP Mathematics RTI norms exist for grade levels K through 11. As ASLAI scores are by age rather than grade, we converted the MAP grades to age equivalents, based on those used by the Test of Early Mathematics Ability - 3 (TEMA-3; Ginsburg \& Baroody, 2003) and calculated MAP Mathematics RTI norms for ages 5- 16. Although the TEMA-3 only goes up to age 8 ( $2^{\text {nd }}$ grade, 7 years old, $3^{\text {rd }}$ grade, 8 years old $)$, we felt that we could expand how we used the TEMA-3 age equivalents to match age to grade for ages older than 8 years.

The student sample in the current analysis ranges from 8 to 18; thus, we recognize there is not a perfect match between the MAP Mathematics RTI norms and our own dataset. These are reflected in the design of Table 3.

For this analysis, we chose a descriptive approach using the end-of-year norms as the metric of comparison for DHH mean scores. These results are presented below (Table 3). We also calculated two additional columns, the low bound of the end of year mean RTI (End of Year Mean RTI - End of Year RTI Standard Deviation) and the high bound of the DHH Mean RTI (DHH Mean RTI + DHH RTI Standard Deviation). These two columns show mathematically the extent of any overlap between -1 standard deviations for general norms, and +1 standard deviation for the DHH students in our sample population. Thus, covering a wider range than just the typically reported absolute mean or median. The standard deviation "indexes the variability of scores" (Cohen, Cohen, West, \& Aiken, 2003, p. 24). What that means is it frames how the mean is dependent on clusters of data points on either end and that these clusters can pull the mean back or forth depending on how many data points are in these clusters and where they are relative to the mean.

$<$ INSERT TABLE 3 HERE $>$ 
The data indicate that from ages 8-16 the RTI norms of our DHH sample are less than the RTI norms of the norming population of the MAP Mathematics test. Additionally, the norms for DHH students who are aged 17 are less than the norms for the last available MAP RTI norms. The data also show a flattening of scores for DHH participants from ages 10 to 13 . During these four years, mean RTI scores hover around 192. However, when the upper bound of DHH mean RTI scores are compared to the lower bound of the general normed RTI scores, a different picture of DHH mathematical abilities emerges. The DHH upper bound scores were higher than the normed lower bound scores at every age except 8,12 , and 14 . For the latter two age groups, the difference between the normed RTI lower bound and the mean RTI upper bound for DHH students was a matter of decimal points. In Figure 2 we visualize the distribution of data using density plots. Density plots show not only the number of data points through size, but also the range of scores. Within the density plot, we also show lines connecting the mean RTI scores for native and nonnative signers. The circles are the normed RTI unit lower bounds for the MAP Mathematics and the triangles are the normed RTI units.

$<$ INSERT FIGURE 2 HERE $>$

The data in Figure 2 show different distributions of MAP RTI scores depending on access to language at home (SIGNING STATUS). We found that the mean RTI units are higher overall for native signers than for nonnative signers. The range of scores for native signers show that many of these students score at least within the range of the MAP RTI lower bounds and the normed MAP RTI score. Most of the native participants have scores that approximate the MAP RTI lower bounds for ages $10,11,12,16$, and 17 . The data also show that some native signers reach and exceed the MAP RTI normed score from ages 9 through 15 . While nonnative signers 
appear to have lower scores than native signers across the board, they do reach the normed MAP RTI lower bound scores for ages 9, and 13 - 18. Ages 14, 15, and 18 meet and exceed the MAP RTI normed score.

Based on this initial analysis, we wanted to further examine the DHH students who are meeting and exceeding both the normed MAP RTI lower bounds and the MAP RTI norms. First, we examined the percentage of native and nonnative signers who have scores higher than both the normed MAP RTI lower bounds and the MAP RTI norms. Second, we did a profile analysis of the type of DHH student who can meet MAP RTI norms based on the background data we have on each student.

Table 4 presents the percentage of native and nonnative signers who have scores higher than both the normed MAP RTI lower bounds and the MAP RTI norms.

\section{$<$ INSERT TABLE 4 HERE $>$}

We then looked at each of the students who scored at or above their age group's normed MAP RTI scores to see if any patterns emerged. 13 students reached this criterion and we considered these participants to be "achieving." Data for the 13 participants are listed in Table 5. The data indicate that the average age for achieving DHH participants is 12.9 years. These students are largely native signers and more likely male ( 8 vs. 5). Eight of the participants have no diagnosed learning disability. Two are suspected of having a learning disability, but are not diagnosed, one has a formally diagnosed learning disability. All achieving DHH participants, with the exception of one, have very high ASL vocabulary scores, with $8(62 \%)$ of them having scores higher than $90 \%$. Of the 5 scores lower than $90 \%$, three were from participants aged 10 and younger. One 15-year-old, nonnative male signer demonstrated low ASL vocabulary 
proficiency, but high mathematics skills. However, that specific participant also scored above MAP reading RTI norms (224 vs. 222.9) indicating strong proficiency in printed English.

\section{$<$ INSERT TABLE 5 HERE $>$}

To sum, the likely high performing DHH student is a middle school male student, without a learning disability, with native ASL signing skills, and high ASL vocabulary abilities. We stress that the gender results do not mean that males are better at math than females but are a likely result of societal stereotypes encouraging males to pursue math learning.

This section address research question (2) What factors (e.g. age, gender, language input (signing status), ASL vocabulary, and learning disability) influence how DHH students perform on the MAP Mathematics subtest?

Our second research question focused on factors that affect performance on the MAP Mathematics subtest for DHH children. We looked at the following factors: a) chronological age, b) signing status (native vs. non-native), c) ASL vocabulary abilities, d) identified gender (male vs. female), and e) learning disability (none, suspected but not diagnosed, and diagnosed learning disability). We predicted that each factor would have the following effects on the MAP Mathematics RTI scores:

- As chronological age grows, RTI scores will also grow.

- Native signers will have higher average scores than non-native signers.

- DHH children with better ASL vocabulary will show higher RTI scores.

- Males will have higher average scores than females.

- Those without any learning disabilities will have better scores than both those suspected of, but not identified with one, and those identified with a learning disability. 
- Those suspected of a learning disability, but not identified with one, may have better scores than those identified with a learning disability and should lag behind students without a known or suspected learning disability

To answer our second question, we used a random effects mixed model approach following Baayen, Davidson, and Bates (2008). The random effects mixed model approach has been used successfully in several other papers published by our team, including Henner et al., (2018) and Novogrodsky et al., (2017). Results (see Table 6) show that all factors listed above were significant predictors of MAP Mathematics scores.

1. Age: As chronological age increased, MAP RTI units also increased by an average of 2.49 points per year $(\mathrm{Chi} \mathrm{Sq}(1)=47.76, \mathrm{p}<.001)$.

2. Signing Status: Native signers outperformed nonnative signers by an average of 6.78 RTI units $($ Chi $\mathrm{Sq}(1)=.004, \mathrm{p}<.01)$.

3. ASL Vocabulary: Vocabulary knowledge lent itself to a slope of 38.51 RTI units depending on the mean scores of the Antonym and Synonym tasks $(\mathrm{Chi} \operatorname{Sq}(1)=68.41, \mathrm{p}$ $<.001)$.

4. Gender: Males outperformed females by an average RTI score of $5.38(\mathrm{Chi} \operatorname{Sq}(1)=5.38$, $\mathrm{p}<.005)$

5. Learning Disability: Lastly, disability diagnosis predicted average RTI scores (Chi Sq(2) $=18.73, \mathrm{p}<.001)$. Those suspected of a diagnosis, but without a formal diagnosis had RTI scores on average 7.34 less than those without a disability. And those who had a formal learning disability diagnosis had scores that were 12.5 points less than those without a disability. 
$<$ INSERT TABLE 6 HERE $>$

\section{Discussion}

Three questions guided this study. We begin our discussion with research question 1

\section{(1) How do the MAP Mathematics scores of the DHH participants compare to the RIT} units age adjusted appropriate normed means?

We wanted to investigate if there was an overlap between the standard deviations in $\mathrm{DHH}$ and hearing participants and if there were DHH data points within the overlap. Within this overlap, the scores of DHH students $(M+S D)$ met or exceeded the scores of hearing students $(M$ - SD) in every single comparison except one. The main exception occurred in the 8 year old group, yielding a 5 point difference, a very slight difference when considering the scale. This is remarkable considering that DHH students learn mathematics in variable language environments (and often in a second language as hearing educators typically are not fluent in ASL, DHH students' first/natural language), or from teachers who may also not be skilled in teaching mathematics (Kelly, Lang, \& Pagliaro, 2003; Pagliaro, 1998). Lack of fluency in ASL impacts teaching of mathematics in that many mathematics concepts do not have one to one correspondence between English words and ASL signs requiring non fluent ASL educators to resort to English or worse, to artificially creating a sign for a mathematics concept (Müller de Quadros \& Hoffmeister, 2020; Henner, Hoffmeister, \& Reis, 2017). Furthermore, DHH students must contend with possible language deprivation in addition to the same pressures hearing students experience that can deflect mathematics acquisition curves (e.g. learning disabilities, gender expectations). 
Our efforts may indicate that while on the surface, it appears that DHH students do not do as well as their hearing cohort on the MAP mathematics subtest, an analysis of variability demonstrates that DHH do better than the expected narrative. In this sample sixty-one (24\%) DHH students performed better than the M-SD of hearing students and $13(5 \%)$ did better than the age-related mean score for hearing participants. Thus, our results show that we should not be focused on simple means analyses when determining DHH students' performance in mathematics. Instead, we must consider other approaches to the data that give us a clearer picture of DHH students' performance. Most importantly, the data must be contextualized, as DHH people are not a homogenous group. If the goal of specialized education is to focus on the needs of the individual, then the individuality that each participant brings to the research dataset must be considered. Essentialized statements, such as that referring to reading (i.e., "DHH people read at a $4^{\text {th }}$ grade level") must be erased and replaced with information that describes the complexity and nuance of how we measure the academic scholarship and skills of DHH participants relative to their life experiences of being deaf or hard of hearing in a hearing society that makes little allowance for full access to language.

(2) What factors (e.g. age, gender, parental hearing status, ASL vocabulary, and learning disability) influence how DHH students perform on the MAP Mathematics subtest?

The issue of variability compels us to drill deeper into the $\mathrm{DHH}$ population and move away from treating DHH students as a group as is the case in almost all research studies. DHH students' identities are not simply Deaf or hard of hearing; DHH students are comprised of multiple identities and multiple unique experiences. Thus, we looked at multiple factors that the literature has shown to be significant including participants' age at testing, identified gender, suspected or identified learning disability, and ASL (vocabulary) knowledge, and signing status- 
of parents (e.g., native/non-native signer/language user). Age and gender were chosen as independent controlling variables due to typical age-related developmental patterns and culturecentric influences on gender. Specifically, we considered the explicit and implicit discouragement of mathematics learning and involvement in STEM (Science, Technology, Engineering, Mathematics) for girls and women. We were additionally curious to see if a group of DHH children who do not have full access to the community language and its culture would show similar effects. Below, we discuss the results.

Age

As expected, there was a significant effect of age on performance on the MAP mathematics subtest. Older participants generally performed better than younger participants. A closer breakdown of the scores by age and parental hearing status was seen in Figure 2. In general, the MAP mathematics scores improved for each year cohort. While we cannot generalize these findings outside of the participant group researched here, we did notice that some years did not see any improvement in scores, and some years saw the mean scores trending downwards. We suspect that flat trending scores represent a transition to harder mathematics subject areas (e.g., trigonometry, algebra). This may also indicate the impact of language fluency in presenting mathematical concepts. The inability to use ASL fluently restricts the amount, type and level of mathematics concepts that could be presented to DHH students, especially in the higher grades. As a possible indicator of this phenomena, anecdotally speaking, we point out that downward trending scores show participants who were proficient in mathematics likely transferred to schools where there would be opportunities to participate in advanced classes where ASL fluent instructors could deliver appropriate mathematics content. We would also not rule out the possibility of these DHH students transferring to integrated classrooms (with hearing 
students) with skilled interpreters further supporting the impact of ASL fluency on delivering mathematical concepts.

Gender

The data presented a significant effect of gender, with male identifying participants scoring overall higher on the MAP assessment than female identifying participants. The results align with demonstrated gender effects in mathematics performance. We stress that our results do not show that males are better than females at mathematics, even in DHH populations. What our results demonstrate is that cultural norms that support male achievement in mathematics trickle into DHH groups, regardless of language barriers and community differences. It appears that cultural norms regarding males and females are strong enough that DHH children pick up on them even within variable language environments. It is possible that teachers of the DHH, who are largely women, may reflect their own cultural biases and feelings of mathematics inadequacy onto their students, a phenomenon called stereotype threat (see Tomasetto, Cadinu, \& Romana Alparone, 2011 for a discussion on stereotype threat in parents and Shapiro \& Williams, 2011 for an overall discussion on stereotype threat).

\section{Parental Hearing Status}

While recent efforts show that in many areas, parental hearing status is not as significant as the early input of ASL (see Henner et al., 2018 for a discussion), we still often use it as a controlling variable. On the whole, DHH children who have full access to language at home do better than DHH children who do not. Here, our results showed that parental hearing status did have a significant effect on the mathematics abilities of the DHH children. Of the 13 participants who performed better than the normed MAP RTI scores, 9 had Deaf parents. Yet when looking at the density graphs in Figure 2, the distribution of scores in native and non-native groups 
overlap substantially. The data, however, are stratified in that while non-native signers are able to do as well on the MAP mathematics subtest as their native signing peers, the latter seem to have an advantage. One possibility for these results is from research by Pagliaro and Kritzer (2010; in prep) which showed the importance of explaining about mathematics and numeracy concepts around children. DHH children with Deaf signing parents have access to an increase of "math talk" which has been shown to correlate with better mathematics performance in hearing students (Klibanoff et al., 2006). As always, we emphasize that disparities in the scores between DHH children with access to language at home and those who have limited access to language at home are not insurmountable. Given a Signed Language rich environment at school with peers and adults who also provide Signed Language input, DHH children who have Signed Language access at home can improve their proficiency to the point where they are on par with native signing peers (Henner et al., 2018). One concern evidence from the data is that while white participants only made up $26 \%$ of the sample population, they represented $78 \%$ of the 13 who scored above MAP Norms. The disparity in math achievement even within this small group will require future research as it is similar to pedagogy challenges faced by hearing children of color (see Berry, Ellis, \& Huges, 2014 for a discussion on this topic).

\section{ASL Vocabulary}

To further demonstrate the impact of ASL (language) fluency we analyzed the role of ASL vocabulary knowledge on mathematics scores. Hrastinski and Wilbur's research (2016) showed that ASL proficiency translates into better scores on the MAP mathematics subtest. Results from the present study support this finding with nearly quadruple the participants, demonstrating a clear connection between ASL vocabulary proficiency and mathematics scores on the MAP. The findings also add to the general mathematics research showing the positive 
relationship between early and full access to a true language and mathematics knowledge. To sum, we believe our results encourages the use of fluent ASL in the deaf education mathematics classroom. These results also neatly fit in with Andin, Fransson, Dahlstom, Ronnberg, \& Rudnet (2019)'s demonstrations that there is no real difference in how the brain processes numeracy via signed language phonology or a spoken language phonology. For the brain, language is language and mathematics is mathematics.

\section{Learning Disabilities}

Finally, we compared the performance on the MAP mathematics subtest of three groups of DHH participants, those without an identified learning disability, those suspected of having one, and those who are identified as having a learning disability. As predicted, those with an identified learning disability did not perform as well as those without an identified learning disability. DHH participants suspected of having a learning disability also did not do as well as

those who were not identified as having one, but better than those identified as having a learning disability. However, having a learning disability or being suspected of one does not automatically mean that mathematics achievement is impossible for DHH children. One participant who scored better than the normed RTI for their age group was identified as having a learning disability and another high scorer was suspected of having one. Having an LD does not necessarily impact learning mathematics.

When considering these results, there are two points to keep in mind. First, the label "learning disability" covers a wide range of challenges, many of which have little to do with mathematics. Thus, we do not know the specifics of the learning disability identification or suspicion in our sample of students. A student can have a reading learning disability (e.g., dyslexia) and not a mathematics learning disability (e.g., dyscalculia), for example. Although 
having a reading disability can impact the measurement of mathematical knowledge since almost all measurement tasks are in English print, the point stands. Second, the process of identifying learning disabilities in DHH students is controversial given the identification process assumes a typical language accessible environment. Many of the identifiable behaviors of learning disabilities are actually related to language deprivation in this population (see Walker, Henner, \& Hoffmeister, 2017 for a discussion on this topic). More to the point, Walker et al. showed that teachers of the deaf were often inaccurate when determining what constitutes a learning disability in DHH children. Additionally, deaf children tend to be diagnosed with disabilities related to learning and attention at greater rates than hearing children (Greco, Beresford, \& Sutherlands, 2009; Bailly, Dechoulydelenclave, \& Lauwerier, 2003). Without additional kinds of testing, preferably ethnographic (see Hou \& Kousters, 2019 for a discussion on ethnographic assessment), we cannot know if the participants in the present study have an identified learning disability that would require specific and knowledgeable interventions to promote mathematics achievement, or if the participants may be language deprived but present as having a learning disability. Either situation requires extensive and individualized targeted education plans.

Still, our results suggest that DHH students who are suspected or who identified with learning disabilities struggle in their classrooms more so than DHH students without an identified learning disability. Teachers can make note of strategies that are more or less successful with each student and adopt a more Universal Design for Learning (UDL) in their classroom by varying approaches and products of instruction. Classrooms are often comprised of students with a wide range of needs and learning modes (Hitchcock \& Stahl, 2003). Lesson plans with varied activities, select grouping of students, and matching products of meeting differential learning styles can better address individual needs of students. Additionally, teachers should 
ensure that DHH students have access to the appropriate linguistic support in classrooms. This requires that teachers themselves are fluent in ASL or that qualified, fluent ASL educational interpreters, knowledgeable in mathematics, are appropriately paired to the DHH child. However, we strongly stress that educational interpreters should not be considered when the students are at risk of language deprivation (see Caselli, Hall, \& Henner, 2020). It is critical to learning to have an accessible language environment.

\section{Final Thoughts, Limitations, and Recommendations for Future Research}

In a direct comparison of the mean MAP mathematic scores, DHH participants in this sample did not perform as well as the normed mean RTI units. However, we argue that these results need to be contextualized. Some deaf people performed better than hearing counterparts. Some scored at or slightly below norms. Overall, the results were variable as research with DHH populations tend to be.

Our goal was to find ways to examine data from a different lens. The literature to date tends to focus on gaps between DHH children and hearing children without taking into consideration factors that will influence performance such as language deprivation, inaccessible environments, insufficient parent, teacher, and administrator signing skills, and low cultural expectations. An application of DST to this research population reveals the need to examine the different factors which can influence mathematical performance in our studied population. Accordingly, we looked for other ways to analyze the data to find ways to represent the mathematics achievement of a group of DHH students and to determine what factors might have contributed to the results.

We began this article by examining how researchers tend to present and interpret the mathematics performance by DHH students as lagging behind hearing peers. Yet, as we stress 
repeatedly, researchers often forget that DHH youth are not just Deaf or hard of hearing. As learners within the larger general population, DHH students vary by gender/sex, age, race, culture, language, and disability. They may be contending with family situations that could derail learning, or educational approaches that do not support their individuality, full access to their language, or their emotional well-being. Many educators hold low expectations of DHH students, accepting the standardized measured levels of achievement as standard "for deaf kids." As a result, blame for the lack of learning is because they are Deaf and not because of observable characteristics of teaching and the environment. Despite these challenges, we know that some DHH children do as well as or better than their hearing peers in academia. Some of their success may be attributed to resilience (see Listman et al., 2011), but resilience is an individual trait that is not attributable to all deaf students. We believe all DHH students have the capacity to learn and to succeed. To understand how to better analyze the data we acquired from our participants so that we might gain insight into successful DHH youth, we employed DST, helping us reframe our thinking and consider the results we received in a more global context. The variables we chose were limited by what was available in the dataset. It is important to remember that any measurement model cannot control all observed and unobserved factors.

Using the mathematics subtest of the MAP and focusing more on standard deviation overlap instead of rigid comparisons of the mean, results demonstrated that many DHH participants score close to or in the overlap of standard deviations indicating approximate performance to hearing peers. Viewing achievement levels this way provides a very different picture by which teachers should plan mathematics instruction, not from an insurmountable deficit view, but from a positive expectation of DHH student performance. Although looking at standard deviation overlaps is another way to interpret the data, it still does not provide a 
reasonable explanation for why some DHH students struggle in mathematics. While the current study cannot yet provide an adequate explanation for this phenomenon, we provide a different, possible solution to examining performance data and suggestions for capitalizing on DHH students' mathematic abilities. Researchers of deaf populations need to continue to explore mathematical modeling that contextualizes their assessment performance while contextualizing data results. However, we all must be aware that purely quantitative results do not provide qualitative reasoning for why deaf individuals perform on assessments the way they do.

We suggest that teachers plan mathematics lessons for DHH students that support and build upon the achievement that these students display, while also recognizing the DHH learner's unique needs (Pagliaro, 2015). Capitalizing on linguistically accurate signed communication with DHH students is essential to support this instruction (Kurz \& Pagliaro, 2020). In addition, given our results that solidly show that ASL vocabulary knowledge translates into likely success in mathematics, we strongly support the results from Hrastinski and Wilbur (2016) and promote teacher fluency not only in signed languages overall, but in application of mathematics concepts through signed languages (Kurz \& Pagliaro, 2020; Pagliaro \& Kurz, 2021).

Because our results indicate that better signing skills in DHH children are more likely to result in higher mathematics performance, we additionally suggest that DHH children be exposed to a fully accessible and true language early and from more fluent models in the home environment and the school. While as a field, we cannot control whether parents of DHH children acquire enough signed language to become proficient signers, we can ensure that DHH children have access to qualified fluent signing teachers of DHH and qualified fluent signed language interpreters. We encourage those professionals who work with signing DHH students to not only become fluent ASL signers, but to also make use of the vast repository of STEM 
signed language corpora (e.g. ASLClear, aslclear.org; Atomic Hands, atomichands.com) and literature (Kurz \& Pagliaro, 2020) where they can better learn how to incorporate specific scientific and mathematical concepts into age appropriate instruction. From a teacher training perspective, our work evidences the need to implement training to attain ASL fluent teachers and specific training in how to teach and present mathematical knowledge to all ages of signing DHH students. As a specific support, we encourage current and future educators of the Deaf to consider ways that they can improve their signed language abilities such that they can use the available properties of ASL to demonstrate both entry level and higher order STEM concepts. 


\section{References}

Allen, T.E. (1986). Patterns of academic achievement among hearing impaired students: 1974 and 1983. In A.N. Schildroth \& M.A. Karchmer (Eds.), Deaf Children in America (pp. 161206). San Diego: College Hill Press.

Allen, T. E. (1995). Demographics and national achievement levels for deaf and hard of hearing students; Implications for mathematics reform. In C. H. Oietz (Ed.), Moving Toward the Standards - A National Action Plan for Mathematics Education Reform for the Deaf (pp. 41-49). Washington. DC: Pre-College Programs, Gallaudet University.

Andin, J., Fransson, P., Dahlström, Ö., Rönnberg, J., \& Rudner, M. (2019). The neural basis of arithmetic and phonology in deaf signing individuals. Language, Cognition and Neuroscience, 34(7), 813-825. https://doi.org/10.1080/23273798.2019.1616103

Arfé, B., Lucangeli, D., Genovese, E., Monzani, D., Gubernale, M., Trevisi, P., \& Santarelli, R. (2011). Analogic and symbolic comparison of numerosity in preschool children with cochlear implants. Deafness \& Education International, 13(1), 34-45. https://doi.org/10.1179/1557069X11Y.0000000002

Baayen, R. H., Davidson, D. J., \& Bates, D. M. (2008). Mixed-effects modeling with crossed random effects for subjects and items. Journal of Memory and Language, 59(4), 390-412. https://doi.org/10.1016/i.jml.2007.12.005

Bailly, D., Dechoulydelenclave, M. B., \& Lauwerier, L. (2003). Hearing impairment and psychopathological disorders in children and adolescents. Review of the recent literature. L'Encephale, 29(4 Pt 1), 329-337. doi:ENC-9-2003-29-4-0013-7006-101019-ART6 
Baldo, J. V., \& Dronkers, N. F. (2007). Neural correlates of arithmetic and language comprehension: A common substrate? Neuropsychologia, 45(2), 229-235. https://doi.org/10.1016/j.neuropsychologia.2006.07.014

Barbosa, H. H. (2013). Habilidades matemáticas iniciais em crianças surdas e ouvintes. Cadernos CEDES, 33(91), 333-347. https://doi.org/10.1590/S0101-32622013000300003

Bernardo, A. B. I., \& Calleja, M. O. (2005). The effects of stating problems in bilingual students' first and second languages on solving mathematics word problems. The Journal of Genetic Psychology, 166, 117-128. http://doi.org/10.3200/GNTP.166.1.117-129

Berry III, R. Q., Ellis, M., \& Hughes, S. (2014). Examining a history of failed reforms and recent stories of success: Mathematics education and Black learners of mathematics in the United States. Race Ethnicity and Education, 17(4), 540-568. https://doi.org/10.1080/13613324.2013.818534

Butterworth, B. (2008). Developmental dyscalculia. Child neuropsychology: Concepts, theory, and practice, $357-374$.

Caselli, N. K., Hall, W. C., \& Henner, J. (2020). American Sign Language Interpreters in Public Schools: An Illusion of Inclusion that Perpetuates Language Deprivation. Maternal and Child Health Journal. https://doi.org/10.1007/s10995-020-02975-7

Chen, X., \& Li, Y. (2008). Research in brief: Language proficiency and mathematics learning. School Science and Mathematics, 108(3), 90-93. https://doi.org/10.1111/j.1949-

\section{$\underline{8594.2008 . t b 17811 . x}$}

Cirino, P., Fuchs, L., Elias, J., Powell, S., \& Schumacher, R. (2015). Cognitive and mathematical profiles for different forms of learning difficulties. Journal of Learning Disabilities. 48(2), 156-175. https://doi.org/10.1177/0022219413494239 
Cohen, J., Cohen, P., West, S., \& Aiken, L. (2003). Applied multiple regression/correlation analysis for the behavioral sciences (3rd ed.). Lawrence Erlbaum Associates.

Cummins, J. (1982). Tests, achievement, and bilingual students. Focus, 9, 1-7.

Davis, S. M., \& Kelly, R. R. (2003). Comparing deaf and hearing college students' mental arithmetic calculations under two interference conditions. American Annals of the Deaf, 148(3), 213-221. https://doi.org/10.1353/aad.2003.0018

De Bot, K., Lowie, W., \& Verspoor, M. (2007). A dynamic systems theory approach to second language acquisition. Bilingualism, 10(1), 7-21. https://doi.org/10.1017/S1366728906002732

De Smedt, B., Taylor, J., Archibald, L., \& Ansari, D. (2010). How is phonological processing related to individual differences in children's arithmetic skills? Developmental Science, 13, 508-520. http://doi.org/10.1111/j.1467-7687.2009.00897

Edwards, A., Edwards, L., \& Langdon, D. (2013). The mathematical abilities of children with cochlear implants. Child Neuropsychology, 19(2), 127-142. http://dx.doi.org/10.1080/09297049.2011.639958

Edwards, L., Figueras, B., Mellanby, J., \& Langdon, D. (2011). Verbal and spatial analogical reasoning in deaf and hearing children: The role of grammar and vocabulary. Journal of Deaf Studies and Deaf Education, 16(2), 189-197. https://doi.org/10.1093/deafed/enq051

Fuchs, L. S., Geary, D. C., Fuchs, D., /',"',",'”;Compton, D. L., \& Hamlett, C. L. (2016). Pathways to third-grade calculation versus word-reading competence: are they more alike or different? Child Development, 87(2), 558-567. https://doi.org/10.1111/cdev.12474

Gatehouse, S., \& Noble, W. (2004). The Speech, Spatial and Qualities of Hearing Scale (SSQ). 
International Journal of Audiology, 43(2), 85-99.

https://doi.org/10.1080/14992020400050014

Geary, D. C., Hoard, M. K., Byrd-Craven, J., Nugent, L., \& Numtee, C. (2007). Cognitive mechanisms underlying achievement deficits in children with mathematical learning disability. Child Development, 78(4), 1343-1359. 10.1111/j.1467-8624.2007.01069.x

Ginsburg, H. P., \& Baroody, A. J. (2003). TEMA-3: Test of Early Mathematics Ability-Third Edition.

Golinkoff, R. M., Hoff, E., Rowe, M. L., Tamis-LeMonda, C. S., \& Hirsh-Pasek, K. (2019). Language matters: Denying the existence of the 30-million-word gap has serious consequences. Child Development, 90(3), 985-992. https://doi.org/10.1111/cdev.13128

Greco, V., Beresford, B., \& Sutherland, H. (2009). Deaf children and young people's experiences of using specialist mental health services. Children \& Society, 23(6), 455469. https://doi.org/10.1111/j.1099-0860.2008.00176.x

Hall, W. C. (2017). What you don't know can hurt you: The risk of impairing visual language development in deaf children. A Research Brieffor the 2015 American Society for Deaf Children Conference, 0(0), 1-4. https://doi.org/10.1007/s10995-017-2287-y

Halvorsen, A. T. \& Molfese, D. (2016). Infant Language Assessment Predicts Later Math Disabilities. UCARE Poster Session, University of Nebraska-Lincoln. http://digitalcommons.unl.edu/ucareresearch/126?utm_source=digitalcommons.unl.edu\%2F ucareresearch\%2F126\&utm_medium=PDF\&utm_campaign=PDFCoverPages

Hart, B., \& Risley, T. R. (1995). Meaningful differences in the everyday experience of young American children. Paul H Brookes Publishing. 
Hartanto, A., Yang, H., \& Yang, S. (2018). Bilingualism positively predicts mathematical competence: Evidence from two large-scale studies. Learning and Individual Differences, 61, 216-227. https://doi.org/10.1016/j.lindif.2017.12.007

Henner, J., Caldwell-Harris, C. L., Novogrodsky, R., \& Hoffmeister, R. (2016). American sign language syntax and analogical reasoning skills are influenced by early acquisition and age of entry to signing schools for the deaf. Frontiers in Psychology, 7(DEC). https://doi.org/10.3389/fpsyg.2016.01982

Henner, J., Novogrodsky, R., Caldwell-Harris, C., \& Hoffmeister, R. (2018). The Development of American Sign Language-Based Analogical Reasoning in Signing Deaf Children. Journal of Speech Language and Hearing Research, 1. https://doi.org/10.1044/2018_JSLHR-L-18-0062

Henner, J., Hoffmeister, R., Reis, J. (2017). Developing sign language measurements for research with deaf populations. In Research in Deaf Education: Contexts, Challenges, and Considerations (pp. 141-160). Oxford University Press.

Hoffmeister, R., Fish, S., Benedict, R., Henner, J., Novogrodsky, R., \& Rosenburg, P. (2013). American Sign Language Assessment Instrument (ASLAI): Revision 4. Boston University Center for the Study of Communication and the Deaf.

Hou, L., \& Kusters, A. (2020). Sign languages. In The Routledge Handbook of Linguistic Ethnography (pp. 340-355). Routledge.

Hrastinski, I., \& Wilbur, R. B. (2016). Academic achievement of deaf and hard-of-hearing students in an ASL/English bilingual program. Journal of Deaf Studies and Deaf Education, 21(2), 156-170. https://doi.org/10.1093/deafed/env072 
Humphries, T., Kushalnagar, P., Mathur, G., Napoli, D. J., Padden, C., Rathmann, C., \& Smith, S. (2016). Avoiding linguistic neglect of deaf children. Social Service Review, 90(4), 589619. https://doi.org/10.1086/689543

Hyde, M., Zevenbergen, R., \& Power, D. (2003). Deaf and hard of hearing students' performance on arithmetic word problems. American Annals of the Deaf, 148(1), 56-64. https://doi.org/10.1353/aad.2003.0003

Kelly, R. R., \& Gaustad, M. G. (2006). Deaf college students' mathematical skills relative to morphological knowledge, reading level, and language proficiency. Journal of Deaf Studies and Deaf Education, 12(1), 25-37. http://dx.doi.org/10.1093/deafed/en1012

Kelly, R. R., Lang, H. G., \& Pagliaro, C. M. (2003). Mathematics word problem solving for deaf students: A survey of practices in grades 6-12. Journal of Deaf Studies and Deaf Education, 8(2), 104-119. http://doi.org/10.1093/deafed/eng007

Kelly, R. R., \& Mousley, K. (2001). Solving word problems: More than reading issues for deaf students. American Annals of the Deaf, 146(3), 251-262. https://doi.org/10.1353/aad.2012.0088

Klibanoff, R. S., Levine, S. C., Huttenlocher, J., Vasilyeva, M., \& Hedges, L. V. (2006). Preschool children's mathematical knowledge: The effect of teacher "math talk." Developmental Psychology, 42(1), 59-69. https://doi.org/10.1037/0012-1649.42.1.59

Kluwin, T. N. (1994). The interaction of race, gender and social class effects in the education of deaf students. American Annals of the Deaf, 139(5), 465-471. https://doi.org/10.1353/aad.1994.0003 
Kritzer, K. L. (2009). Barely started and already left behind: A descriptive analysis of the mathematics ability demonstrated by young deaf children. Journal of Deaf Studies and Deaf Education, 14(4), 409-421. https://doi.org/10.1093/deafed/enp015

Krussel, L. (1998). Teaching the language of mathematics. The Mathematics Teacher, 91(5), $436-441$.

Kuhl, P. K. (2004). Early language acquisition: Cracking the speech code. Nature Reviews Neuroscience, 5(11), 831-843. https://doi.org/10.1038/nrn1533

Kurz, C. \& Pagliaro, C. M. (2020). Using sign languages to teach mathematics to deaf students. In R. Rosen (Editor), Handbook of Sign Language Pedagogy, New York: Routledge.

Lange, C. M., Lane-Outlaw, S., Lange, W. E., \& Sherwood, D. L. (2013). American Sign Language/English bilingual model: A longitudinal study of academic growth. Journal of Deaf Studies and Deaf Education, 18(4), 532-44. https://doi.org/10.1093/deafed/ent027

Lederberg, A. R., Schick, B., \& Spencer, P. E. (2013). Language and literacy development of deaf and hard-of-hearing children: successes and challenges. Developmental Psychology, 49(1), 15. https://doi.org/10.1037/a0029558

Le Fevre, J. Fast, L., Skwarchuk, S., Smith-Chant, B., Bisanz, J., Kamawar, D., \& PennerWilger, M. (2010). Pathways to mathematics: Longitudinal predictors of performance. Child Development, 81(6), 1753-1767. https://doi.org/10.1111/j.1467-8624.2010.01508.x

Levine, S. C., Suriyakham, L. W., Rowe, M. L., Huttenlocher, J., \& Gunderson, E. A. (2010). What counts in the development of young children's number knowledge? Developmental Psychology, 46(5), 1309-1319. https://doi.org/10.1037/a0019671 
Lindberg, S. M., Hyde, J. S., Petersen, J. L., \& Linn, M. C. (2010). New trends in gender and mathematics performance: A meta-analysis. Psychological Bulletin, 136(6), 1123-1135. https://doi.org/10.1037/a0021276

Listman, J., Rogers, K., \& Hauser, P. (2011). Community cultural wealth and deaf adolescents' resilience. In D. Zand \& K. Pierce (Eds.), Resilience in Deaf children: Adaptation through Emerging Adulthood (pp. 279-298). Springer.

Madalena, S. P., Correa, J., \& Spinillo, A. G. (2020). Mathematical knowledge and language in deaf students: The relationship between the recitation of a numerical sequence and Brazilian Sign Language proficiency. Estudos de Psicologia (Campinas), 37, e180175. https://doi.org/10.1590/1982-0275202037e180175

Mann Koepke, K., \& Miller, B. (2013). At the intersection of math and reading disability: Introduction to the special issue. Journal of Learning Disabilities, 46, 483-489. http://dx.doi.org/10.1177/0022219413498200

Mix, K. S. (2009). How Spencer made number: First uses of the number words. Journal of Experimental Child Psychology, 102, 427-444. http://dx.doi.org/10.1016/j.jecp.2008.11.003

Müller de Quadros , R. \& Hoffmeister, R. (2020) The politics of L1 signed language pedagogy. In R. Rosen (Ed.), Handbook on Sign Language Pedagogy, Columbia University.

Newport, E. L., Bavelier, D., \& Neville, H. J. (2001). Critical thinking about critical periods: Perspectives on a critical period for language acquisition/ In: Doupoux E, editor. Language, brain and cognitive development: Essays in honor of Jacques Mehler. Cambridge, MA: MIT Press. pp. 481-502. 
Novogrodsky, R., Henner, J., Caldwell-Harris, C., \& Hoffmeister, R. (2017). The development of sensitivity to grammatical violations in American Sign Language: Native versus nonnative signers. Language Learning, 67(4). https://doi.org/10.1111/lang.12245

Pagliaro, C. M. (2015). Developing numeracy in individuals who are deaf/hard of hearing. In Knoors, H. \& Marschark, M. (Eds.), Educating Deaf Students: Creating a Global Evidence Base. New York: Oxford University Press.

Pagliaro, C. M. (1998). Mathematics preparation and professional development of deaf education teachers. American Annals of the Deaf, 373-379. https://doi.org/10.1353/aad.2112.0137

Pagliaro, C. M., \& Ansell, E. (2012). Deaf and hard of hearing students' problem-solving strategies with signed arithmetic story problems. American Annals of the Deaf, 156(5), 438458. https://doi.org/10.1353/aad.2012.1600

Pagliaro, C. M., \& Kritzer, K. L. (2010). Learning to learn: An analysis of early learning behaviours demonstrated by young deaf/hard-of-hearing children with high/low mathematics ability. Deafness \& Education International, 12(2), 54-76. http://dx.doi.org/10.1179/146431510X12626982043723

Pagliaro, C. M. \& Kurz, C. (2021). Using ASL to navigate the semantic circuit in the bilingual mathematics classroom. In C. Enns, J. Henner, \& L. Mcquarrie (Editors). Discussing Bilingualism in Deaf Children, New York: Routledge.

Pagliaro, C. M. \& Kritzer, K. L. (2017). Math Talk: A descriptive analysis of the mathematics vocabulary and dialogue used naturally by parents and their young deaf/hard-of-hearing children following an intervention [Unpublished manuscript]. Specialized Education Services, University of North Carolina at Greensboro. 
Perez, A. L. \& Alieto, E. (2018). Change of "tongue" from English to a local language: A correlation of mother tongue proficiency and mathematics achievement. The Asian ESP Journal, 14(7.2), 132-150

Powers, S. (2003). Influences of student and family factors on academic outcomes of mainstream secondary school deaf students. Journal of Deaf Studies and Deaf Education, 8(1), 57-78. https://doi.org/10.1093/deafed/8.1.57

Purpura, D. J., Hume, L., Sims, D., \& Lonigan, C. J. (2011). Early literacy and early numeracy: the value of including early literacy skills in the prediction of numeracy development. Journal of Experimental Child Psychology, 110(4), 647-658. http://dx.doi.org/10.1016/j.jecp.2011.07.004

Qi, S., \& Mitchell, R. E. (2011). Large-scale academic achievement testing of deaf and hard-ofhearing students: Past, present, and future. Journal of Deaf Studies and Deaf Education. http://www.jdsde.oxfordjournals.org/cgi/doi/10.1093/deafed/enr028 papers3://publication/doi/10.1093/deafed/enr028

Reilly, D., Neumann, D. L., \& Andrews, G. (2015). Sex differences in mathematics and science achievement: A meta-analysis of National Assessment of Educational Progress assessments. Journal of Educational Psychology, 107(3), 645-662. https://doi.org/10.1037/edu0000012

Reigosa-Crespo, V., Valdés-Sosa, M., Butterworth, B., Estévez, N., Rodríguez, M., Santos, E., ... \& Lage, A. (2012). Basic numerical capacities and prevalence of developmental dyscalculia: the Havana Survey. Developmental Psychology, 48(1), 123. https://doi.org/10.1037/a0025356 
Secada, W. G. (1992). Race, ethnicity, social class, language, and achievement in mathematics. In D. A. Grouws (Ed.), Handbook of research on mathematics teaching and learning: A project of the National Council of Teachers of Mathematics (p. 623-660). Macmillan Publishing Co, Inc.

Seymour, E. (1995). The loss of women from science, mathematics, and engineering undergraduate majors: An explanatory account. Science Education, 79(4), 437-473. https://doi.org/10.1002/sce.3730790406

Shapiro, J. R., \& Williams, A. M. (2012). The role of stereotype threats in undermining girls' and women's performance and interest in STEM fields. Sex Roles, 66(3-4), 175-183. https://doi.org/10.1007/s11199-011-0051-0

Simmons, F., Singleton, C. \& Horne, J. K. (2008). Phonological awareness and visual-spatial sketchpad functioning predict early arithmetic attainment: Evidence from a longitudinal study. European Journal of Cognitive Psychology, 20(4), 711-22. https://doi10.1080/09541440701614922

Sperry, D. E., Sperry, L. L., \& Miller, P. J. (2019). Reexamining the verbal environments of children from different socioeconomic backgrounds. Child Development, 90(4), 1303-1318. https://doi.org/10.1111/cdev.13072

Susperreguy, M. I., \& Davis-Kean, P. E. (2016). Maternal math talk in the home and math skills in preschool children. Early Education and Development, 27(6), 841-857. https://doi.org/10.1080/10409289.2016.1148480

Suskind, D. L., Leffel, K. R., Graf, E., Hernandez, M. W., Gunderson, E. A., Sapolich, S. G., Levine, S. C. (2016). A parent-directed language intervention for children of low 
socioeconomic status: a randomized controlled pilot study. Journal of Child Language, 43(2), 366-406. http://doi:10.1017/S0305000915000033

Toll, S. W. M., \& Van Luit, J. E. H. (2014). The developmental relationship between language and low early numeracy skills throughout kindergarten. Exceptional Children, 81, 64-78. http://dx.doi.org/10.1177/0014402914532233

Tomasetto, C., Alparone, F. R., \& Cadinu, M. (2011). Girls' math performance under stereotype threat: The moderating role of mothers' gender stereotypes. Developmental Psychology, 47(4), 943-9. https://doi.org/10.1037/a0024047

Tuller, L., \& Delage, H. (2014). Mild-to-moderate hearing loss and language impairment: How are they linked? Lingua, 139, 80-101. https://doi.org/10.1016/j.lingua.2013.10.009

Traxler, C. (2000). The Stanford Achievement Test, 9th Edition: National norming and performance standards for deaf and hard-of-hearing students. Journal of Deaf Studies and Deaf Education, 5(4), 337-48. https://doi.org/10.1093/deafed/5.4.337

Wang, W., Jiang, C., \& Fan, Z., (2017). The relation of mathematics and language ability. Asian Social Science, 13(10), 152-158. https://doi.org/10.5539/ass.v13n10p152

Walker, K., Henner. J., \& Hoffmeister, R. (2017). Language deprivation: The neglected factor in learning disability diagnosis in deaf children. Presented at the 2017 AERA Conference. San Antonio, Texas, USA.

Zarfaty, Y., Nunes, T., \& Bryant, P. (2004). The performance of young deaf children in spatial and temporal number tasks. Journal of Deaf Studies and Deaf Education, 9(3), 315-326. https://doi.org/10.1093/deafed/enh034 


\section{TABLES AND FIGURES}

\section{Table 1}

Sample by age and signing status.

\begin{tabular}{lllllllllllll} 
Age (years) & 8 & 9 & 10 & 11 & 12 & 13 & 14 & 15 & 16 & 17 & 18 & Total \\
\hline Native & 15 & 13 & 12 & 9 & 8 & 3 & 7 & 4 & 4 & 4 & 3 & 82 \\
\hline Nonnative & 8 & 9 & 8 & 10 & 10 & 16 & 21 & 18 & 19 & 28 & 28 & 175 \\
\hline
\end{tabular}

Table 2

Distribution of disability ratings in the sample population

\begin{tabular}{llll} 
Rating & 1 (No Disability) & 2 (Suspected & 3 (Confirmed \\
& & Learning Disability) & Learning Disability) \\
\hline Native & $55 \%(\mathrm{n}=45)$ & $33 \%(\mathrm{n}=27)$ & $12 \%(\mathrm{n}=10)$ \\
\hline Nonnative & $35 \%(\mathrm{n}=62)$ & $51 \%(\mathrm{n}=89)$ & $14 \%(\mathrm{n}=24)$ \\
\hline
\end{tabular}


Table 3: Comparison of end of year Mean RTI and SD for hearing and DHH populations

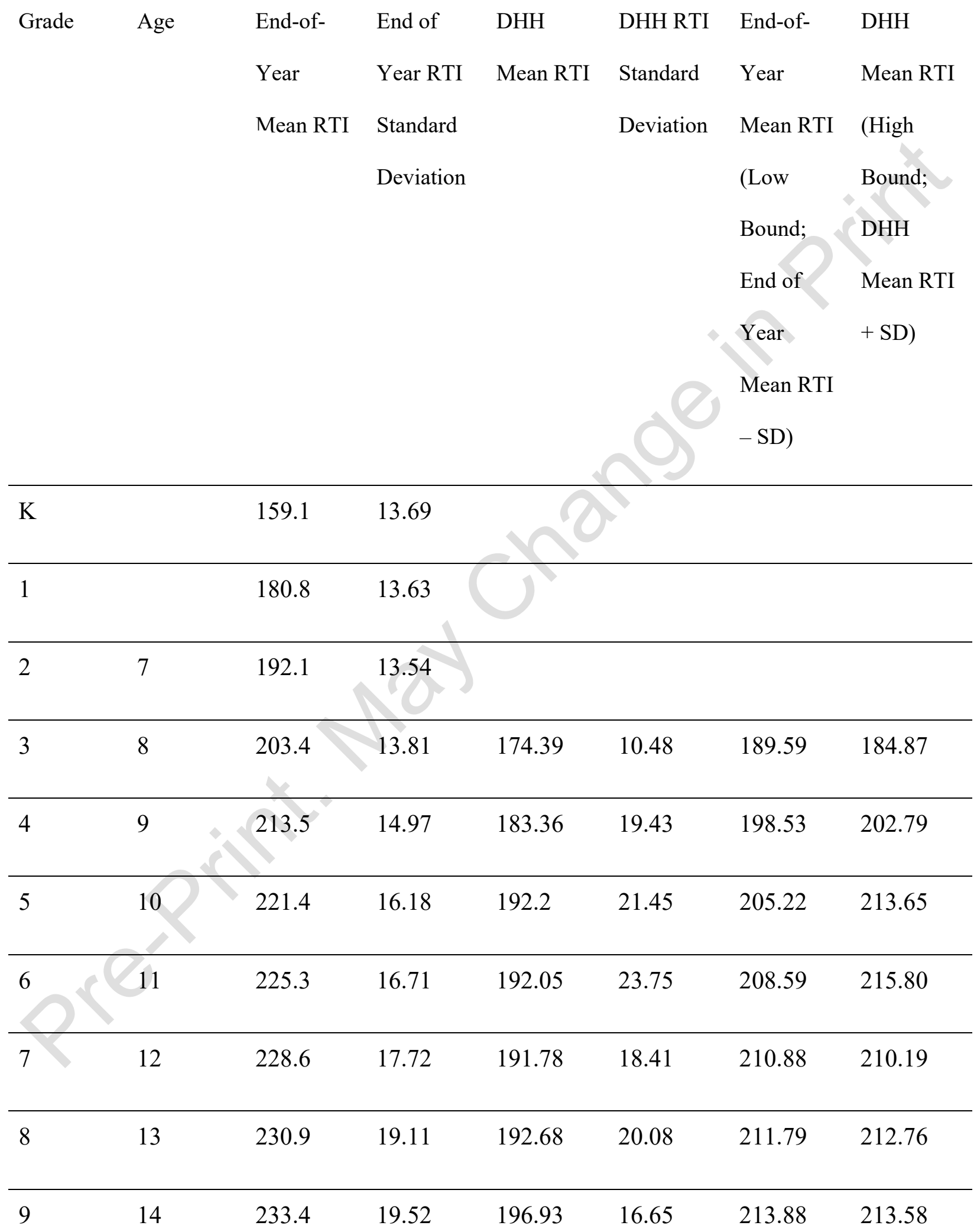




\begin{tabular}{lccccccc}
10 & 15 & 232.4 & 20.96 & 206.68 & 21.42 & 211.44 & 228.10 \\
\hline 11 & 16 & 235 & 21.3 & 208.17 & 22.58 & 213.70 & 230.75 \\
\hline N/A & 17 & & 204.56 & 17.04 & & 221.60 \\
\hline N/A & 18 & & & & & & \\
\hline
\end{tabular}

Table 4

Distribution of percentage reached for normed MAP RIT lower bound and RTI scores by signing status

Percentage Reached Normed MAP RTI Lower Normed MAP RTI Score

Native $\quad 34 \%(\mathrm{n}=28) \quad 11 \%(\mathrm{n}=9)$

Nonnative

$19 \%(n=33)$

$3 \%(n=4)$ 


\section{Table 5}

\section{Listing of all participants who scored above the norms for MAP Math}

\begin{tabular}{|c|c|c|c|c|c|c|c|}
\hline Participant & Chronological & Signing & Gender & Ethnicity & Student & MAP & ASL \\
\hline & Age & Status & & & Rating & Math & Vocabulary \\
\hline & & & & & & RTI & $(\mathrm{x} 100)$ \\
\hline 1 & 18 & Nonnative & $\mathrm{F}$ & Asian & 3 & 241 & 100 \\
\hline 2 & 16 & Nonnative & M & White & 2 & 259 & 92.5 \\
\hline 3 & 16 & Nonnative & M & White & & 254 & 96 \\
\hline 4 & 15 & Native & M & White & 1 & 263 & 100 \\
\hline 5 & 15 & Nonnative & M & White & 1 & 246 & 17.5 \\
\hline 6 & 14 & Native & M & Latinx & 1 & 241 & 100 \\
\hline 7 & 13 & Native & M & Latinx & 1 & 244 & 89 \\
\hline 8 & 12 & Native & $\mathrm{F}$ & White & 2 & 230 & 96 \\
\hline 9 & 11 & Native & M & White & 1 & 230 & 92 \\
\hline 0 & 10 & Native & $\mathrm{F}$ & White & 1 & 229 & 96 \\
\hline 11 & 10 & Native & M & White & 1 & 237 & 89 \\
\hline 12 & 9 & Native & $\mathrm{F}$ & White & 1 & 218 & 71 \\
\hline
\end{tabular}


13

9

Native $\quad F \quad$ White 1

219

89

Table 6: Mixed effect regression analysis using MAP as the dependent variable and Age, Signing Status, Native/non Native, Vocabulary, Gender, and Student Rating as independent variables
Estimate
Standard
t-value
Chi-Sq
p-Value

(Beta) Error

Fixed Effects

Age

2.49

.034

7.25

47.76

$\mathrm{p}<.001$

Signing

.004

$\mathrm{p}=.009$

Status

(Native)

NonNative $\quad-6.78$

2.33

$-2.90$

Vocabulary

38.51

4.13

9.31

68.41

$\mathrm{p}<.001$

Gender

(Female)

Male

5.38

1.89

2.84

.005

$\mathrm{p}=.001$ 
Student

18.73

$\mathrm{p}<.001$

Rating (No

Disability)

\begin{tabular}{llll}
\hline Suspected & -7.34 & 2.15 & -3.41 \\
\hline Diagnosed & -12.50 & 3.11 & -4.01 \\
LD & & \\
\hline Random & Variance & Standard \\
Effects & & Deviation \\
\hline Intercept & 78.25 & 8.8
\end{tabular}




\section{Figure 1}

An example of the ASLAI platform

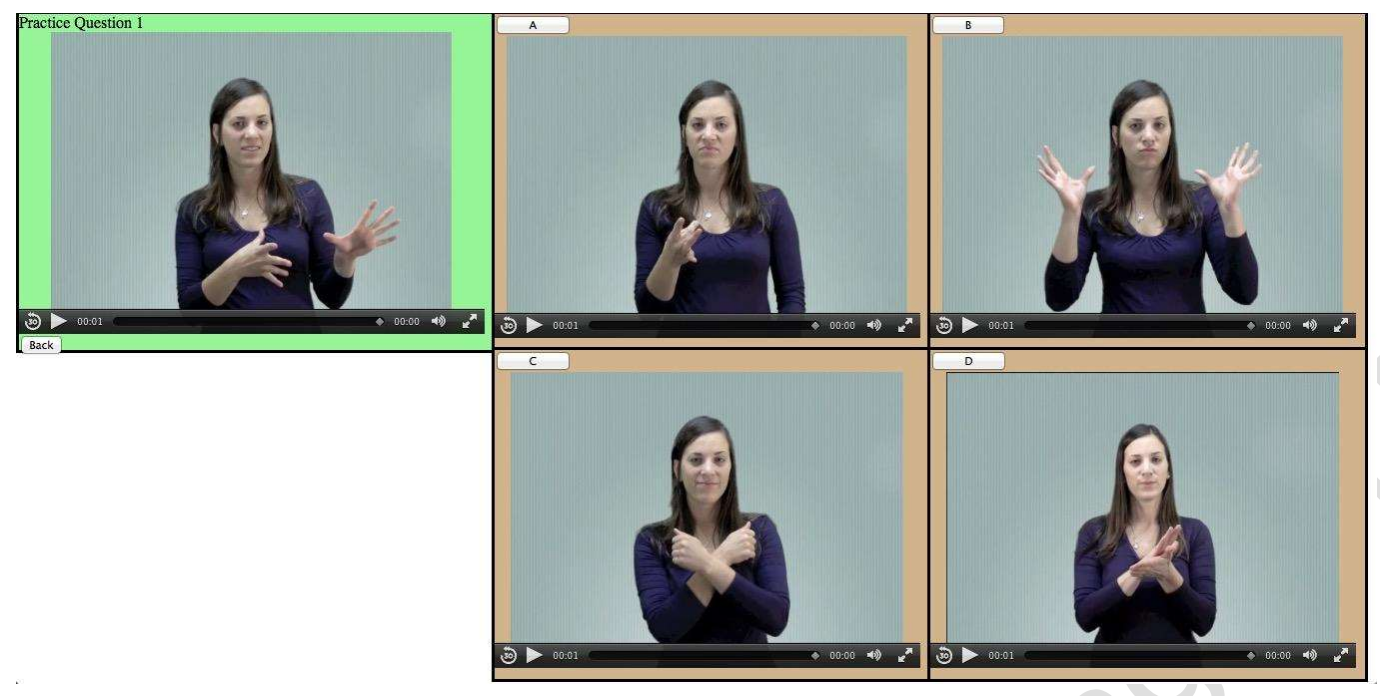

Figure 2

Graph of RTI score distribution by age and signing status. 


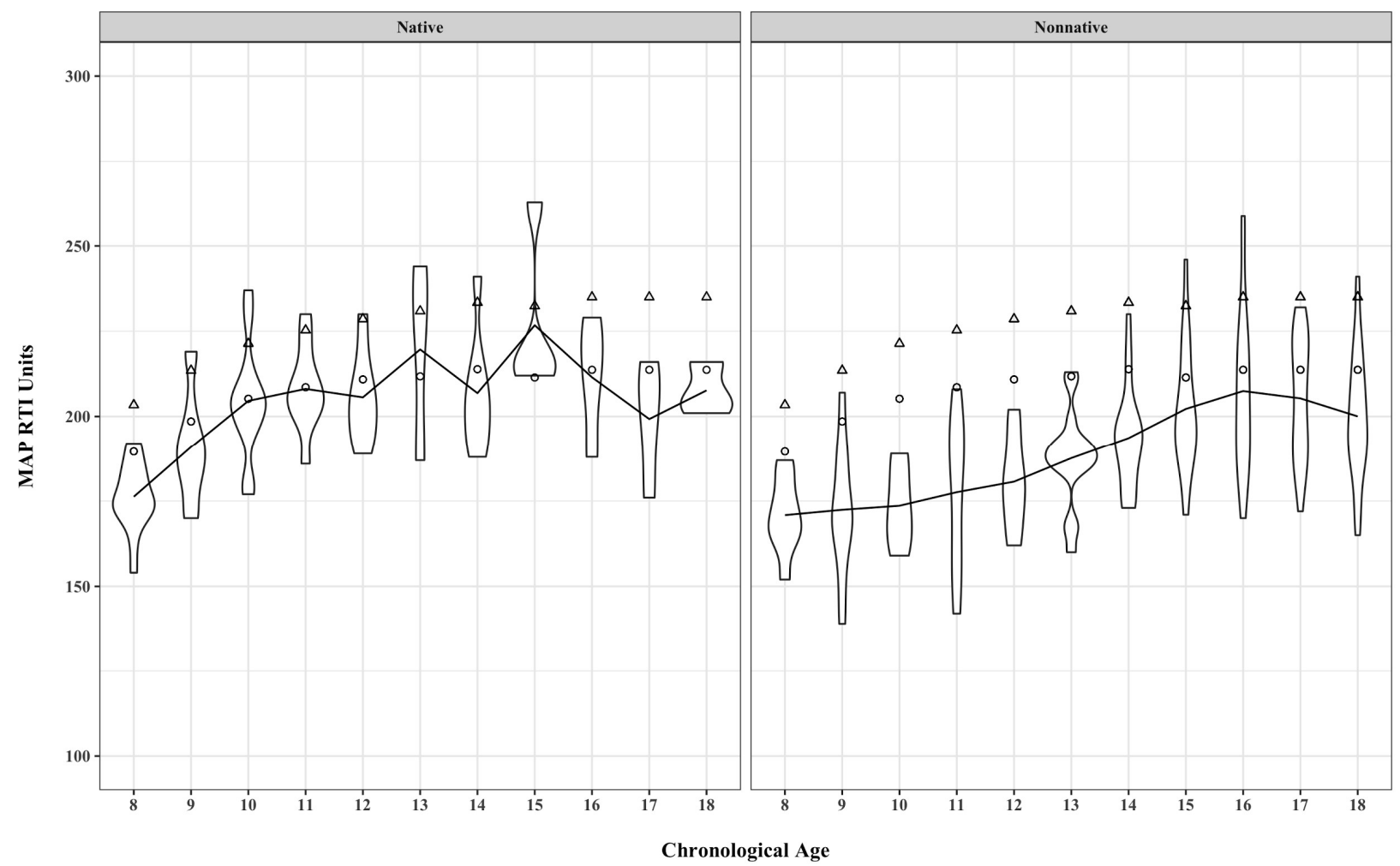

Note: Circles represent the lower bound RTI score and triangles represent the MAP normed score 